\title{
TRENDS IN THE INCIDENCE OF BREAST CANCER FOLLOWING THE RADIOLOGICAL ACCIDENT IN GOIÂNIA: A 25-YEAR ANALYSIS
}

Marina E. Rocha'1, Rosemar M. S. Rahal², Ruffo Freitas-Junior², Rosangela da S. Corrêa², Danielle C. N. Rodrigues², Edésio Martins², José C. de Oliveira ${ }^{3}$

${ }^{1}$ School of Medicine, Universidade Federal de Goiás - Goiânia (GO), Brazil.

${ }^{2}$ CORA - Centro Avançado de Diagnóstico da Mama, Hospital das Clínicas, Universidade Federal de Goiás - Goiânia (GO), Brazil. 3Population-Based Cancer Registry of Goiânia - Goiânia (GO), Brazil.

Background: The largest radiological accident to occur in any urban area happened in a Brazilian state capital city in 1987 to the detriment of the population and the environment. One major concern regarding deleterious effects in the population was a possible increase in breast cancer incidence rates, since the literature shows that exposure of an individual to ionizing radiation is one of the risk factors for cancer. This study analyzed trends in the incidence of breast cancer over the 25-year period following the radiological accident. Methods: This ecological, population-based study was conducted to determine the incidence of breast cancer in female residents of Goiânia, Goiás, Brazil, between 1988 and 2012. The data were collected from the Goiânia population-based cancer registry. Crude and age-standardized incidence rates were calculated. The Joinpoint software program was used to calculate annual percent changes (APC) in the incidence of breast cancer. Results: Overall, 7,365 new cases of breast cancer were identified, with an annual crude incidence rate of 23.09/100,000 women in 1988 and of 71.65/100,000 women in 2012. The age-standardized incidence rate was $35.63 / 100,000$ women in 1988 and 65.63/100,000 women in 2012. Analysis of the APC showed a significant annual increase of 4.8\% in the incidence between 1988 and 2005 ( $\mathrm{p}<0.0001$ ) followed by stabilization in 2005-2012, with an APC of -3.5\% $(\mathrm{p}=0.1)$. Conclusion: There was an increase in the incidence of breast cancer in the female residents of Goiânia, Goiás in the first 17 years of evaluation (1988-2004) followed by a period of stabilization until 2012. 